\title{
Microstructural Analysis of Friction Stir Butt Welded Al-Mg-Sc-Zr Alloy Heavy Gauge Sheets
}

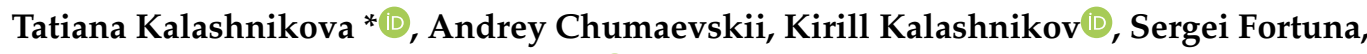 \\ Evgeny Kolubaev and Sergei Tarasov $\mathbb{D}$
}

Institute of Strength Physics and Materials Science, Siberian Branch of Russian Academy of Sciences, 634055 Tomsk, Russia; tch7av@gmail.com (A.C.); kkn@ispms.tsc.ru (K.K.); s_fortuna@ispms.ru (S.F.); eak@ispms.ru (E.K.); tsy@ispms.ru (S.T.)

* Correspondence: gelombang@ispms.ru; Tel.: +7-3822-286-863

Received: 31 May 2020; Accepted: 15 June 2020; Published: 17 June 2020

check for updates

\begin{abstract}
Friction stir welding (FSW) on a heavy gauge sheet of a hereditary fine-grained Al-Mg-Sc-Zr alloy was carried out to study the specifics of plasticized metal flow and microstructural evolution in different sections and zones of the joint. It was found that the stir zone (SZ) macrostructure may contain either a single or many nugget zones depending on the metal sheet thickness and the seam length. The effect of grain kinking in a thermomechanically affected zone (TMAZ) under pressure from the stir zone metal was discovered. The stir zone metal was fine-grained but had a microhardness lower than that of the base metal, which may be explained by the overaging effect of $\mathrm{FSW}$ on the $\mathrm{Al}_{3} \mathrm{Sc}$ precipitates. The tensile strength of the joint was almost equal to that of the base metal (BM). The grain size distributions were obtained in different sections below the sheet surface and away from the exit hole, which allowed us to suggest the specific adhesion-assisted layer-by layer metal transfer mechanism in FSW.
\end{abstract}

Keywords: friction stir welding; aluminum alloy; structure formation; adhesion; metal transfer; mechanical properties

\section{Introduction}

Al-Mg alloys are well-known structural materials that are widely used in various applications including those where welding is a single option joining method. Improving the Al-Mg alloy strength characteristics is achieved by alloying the metals with scandium and zirconium [1-4], which makes them hereditary fine-grained alloys while retaining their corrosion resistance [2,5].

The alloy fine-grained microstructure is stabilized by the precipitation of nanosized $\mathrm{Al}_{6} \mathrm{Mn}, \mathrm{Al}_{3} \mathrm{Sc}$, and $\mathrm{Al}_{3}(\mathrm{Sc}, \mathrm{Zr})$ matrix coherent particles, which first precipitate from a solid solution and then have a pinning effect on the grain boundaries so that even annealing at $723 \mathrm{~K}$ for $16 \mathrm{~h}$ does not increase the grain size [6]. The $\mathrm{Al}_{3} \mathrm{Sc}$ precipitates are the most effective precipitates for pinning the grain boundaries [7]. It is known also [8] that the nanosized $\mathrm{Al}_{3} \mathrm{Sc}$ precipitates are stable against coalescence so that that their mean diameter increased only from 13.5 to $15.4 \mathrm{~nm}$ for 7 days at $350{ }^{\circ} \mathrm{C}$.

Friction stir welding (FSW) is a method used for joining metals in a solid state and is, therefore, often used on metals and alloys that cannot be welded using any fusion welding technique. An Al-Mg-Sc-Zr alloy is an example of such a hardly weldable alloy that and is, therefore, a candidate for joining with friction stir welding. It is common knowledge that this solid state joining method usually forms a fine-grained microstructure in the stirring zone. The presence of the nanosized growth inhibitors in Al-Mg-Sc-Zr is an extra factor that helps retaining the fine-grained structure of the welded metal and thus improving its mechanical characteristics [9]. For example, it was reported [10] that FSW increased the ultimate and yield stresses of the Sc + Zr-alloyed aluminum alloy by 23.8 and $11.9 \%$, respectively. 
Practically a $100 \%$ tensile strength was achieved on the Al-5.4Mg-0.2Sc- $0.1 \mathrm{Zr}$ alloy FSW seam even after annealing [11]. The mechanical strength advantage of the FSW joint compared to that of the TIG on the Al-Mg-Sc-Zr alloy was thus demonstrated [10].

Another positive factor of the FSW-generated fine-grained structure is its potential to take advantage of superplasticity characteristics [12-16] that allow up to $2000 \%$ elongation while retaining microstructural thermal stability at $450{ }^{\circ} \mathrm{C}$ [12].

The effect of $\mathrm{Al}_{3} \mathrm{Sc}$ and $\mathrm{Al}_{3}(\mathrm{Sc}, \mathrm{Zr})$ nanosized precipitates on pinning the fatigue crack tip was also reported [17]. It was shown [18] that friction stir processing improves the corrosion resistance of Al-Mg alloys in a $\mathrm{NaCl}$ aqueous solution.

An important problem in FSW is obtaining a flawless and reliable seam when joining thick sheets. The inhomogeneity and efficiency of metal stirring, enhanced adhesion of metal to the FSW tool, diffusion-controlled FSW tool wear, fast heat removal, and high mechanical loads are factors that aggravate the problems commonly encountered with FSW on aluminum alloy sheets up to $10 \mathrm{~mm}$ thickness. Some technologies require welding heavy gauge sheets or pipes, which then are then machined to obtain the final structure. This requirement makes it necessary to study FSW seams on heavy gauge workpieces.

It may be concluded, therefore, that Al-Mg-Sc and Al-Mg-Sc-Zr alloys not only possess high mechanical characteristics and are weldable using FSW but also that their characteristics can be further improved using FSW, which is a promising research field from both practical and scientific points of view.

The severe thermomechanical impact of FSW on the plasticized aluminum alloy in the stirring zone creates the conditions for the strain-induced dissolution of particles, thereby enriching the solid solution with the alloying elements and facilitating the fast precipitation of particles. This is an element of FSW aspect that has not received much attention in the literature, especially when taking into account the dynamic character of dissolution/precipitation, as well as recrystallization, during the process. This issue becomes even more intriguing when applying FSW to an Al-Mg-Sc-Zr alloy, whose microstructure is known to have high temperature stability. The FSW joint structure formation is determined by the specificity of metal transfer and the role played by the adhesion of plasticized metal to the FSW tool.

The objective of this paper is to study the microstructures and mechanical characteristics of the FSW joint zones obtained on heavy gauge Al-Mg-Sc-Zr alloy sheets.

\section{Materials and Methods}

Hot-rolled 30 and $35 \mathrm{~mm}$ thick $300 \mathrm{~mm} \times 300 \mathrm{~mm}$ sheets of AA1570 and HSS M2 steel FSW tools were used to carry out friction stir welding using an FSP machine PowerStir 345C (Holroyd Precision Ltd., Milnrow, UK) at the facilities of S.P. Korolev RSC Energia Experimental Machine-building Plant ZEM. The shape and parameters of the tools used for the welding are shown in Figure 1. The process parameters were adjusted experimentally to obtain the FSW joints, as shown in Figure 1. The FSW tool rotation rate, traverse speed, and plunging force were $600 \mathrm{RPM}, 10 \mathrm{~mm} / \mathrm{min}$, and $40 \mathrm{kN}$, respectively. The FSW seam can be divided into three zones as shown in Figure 1a, where zones B, S, and H denote the FSW tool plunging zone characterized by insufficient heating plasticization, steady welding, and the FSW tool exit zone, respectively.

The stop-action technique [19] was applied to study the mechanical behavior of the metal in the thermomechanically affected zones (TMAZs) when the FSW tool exit hole was sectioned and then marked as shown in Figure 2. Another series of metallographic views was obtained by EDM cutting the seam by planes normal to the sheet surface and both perpendicular and parallel to the FSW joint line. An EDM cutting machine DK7745 (Suzhou Simos CNC Technology Co., Ltd. Suzhou, China) was used to cut off the samples, which were then ground, polished, and etched to prepare the metallographic section views. 


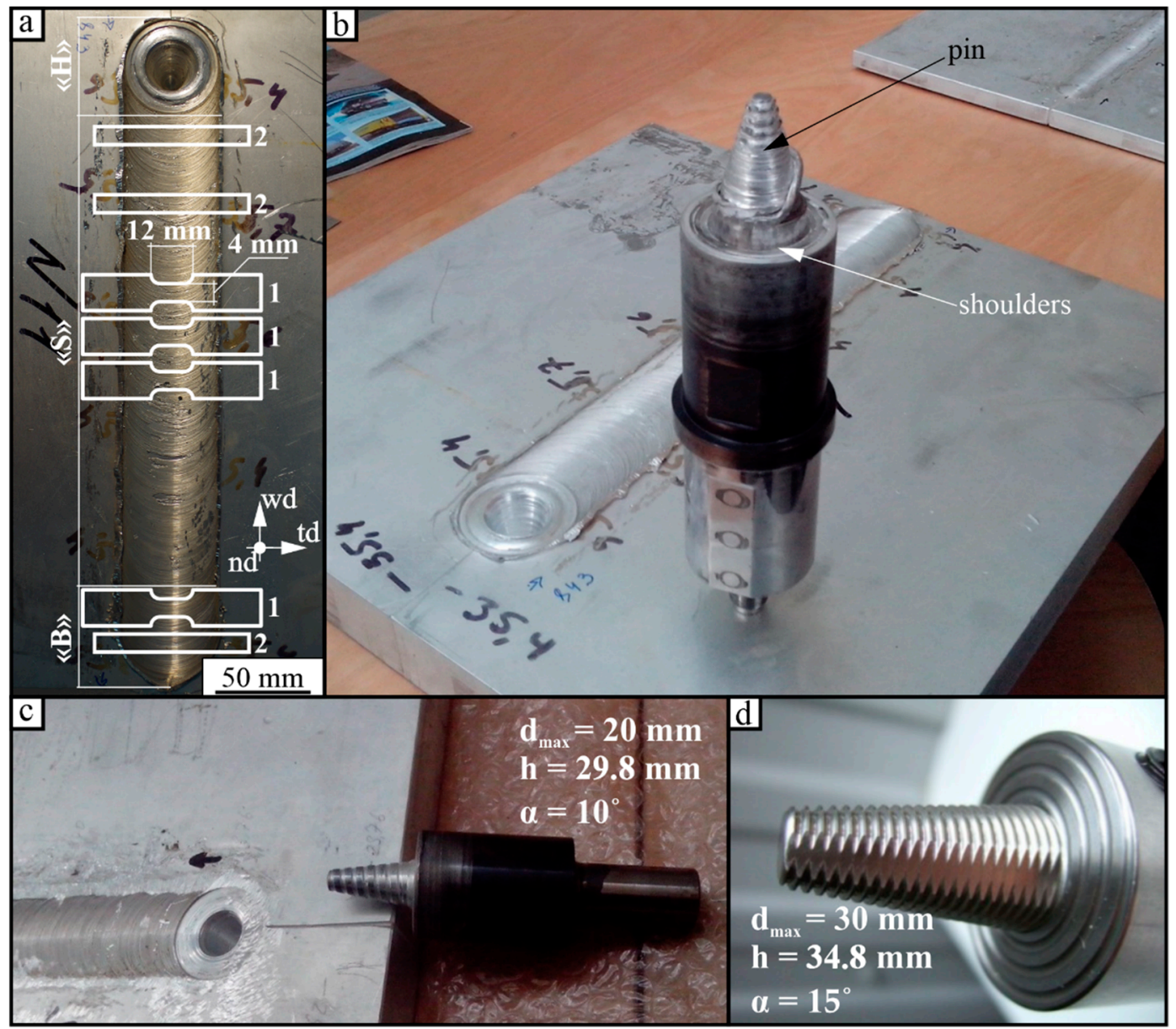

Figure 1. The friction stir welding (FSW) seam zones on a $35 \mathrm{~mm}$ thick AA1570 sheet (a), the FSW tool used for the $35 \mathrm{~mm}$ thick sheet after welding (b), the FSW tool used for the $30 \mathrm{~mm}$ thick sheet after welding (c), and the FSW tool used for the $35 \mathrm{~mm}$ thick sheet before welding (d). 1-tensile specimens; 2-metallographic section views, $\mathrm{d}_{\max }$-the larger pin diameter, $\mathrm{h}$-the pin height, $\alpha$-the taper angle.

The joint strength was tested using a test machine BISS UT-04-0100 (BISS (P) Ltd. Bangalore, India) on samples cut off the seam by a plane perpendicular to the tool travel direction at different distances below the top surface so that the stir zone was located in the middle of the sample's gauge length part (Figure 1). The loading speed was $100 \mathrm{~mm} / \mathrm{s}$.

A microstructural examination was performed using optical microscopes Altami MET 1T(Altami Ltd., Saint-Petersburg, Russia), Olympus OLK41102 (Olympus Corp, Tokio, Japan), SEM and TEM instruments Tescan VEGA 3 (TESCAN ORSAY HOLDING, BRNO, Czech Republic), Zeiss LEO EVO 50 (Carl Zeiss AG, Oberkochen Germany), and JEOL JEM-2100 (JEOL Ltd., Akishima, Japan).

Thin foils for TEM were prepared using EDM cutting, mechanical polishing, and ion thinning to represent the stir zone metal in two perpendicular sections with respect to the joint line. A microhardness tester Duramin-5 (Struers A/S, Ballerup, Danemark) was used to obtain microhardness profiles across the FSW seam zones at a $490 \mathrm{mN}$ load. 


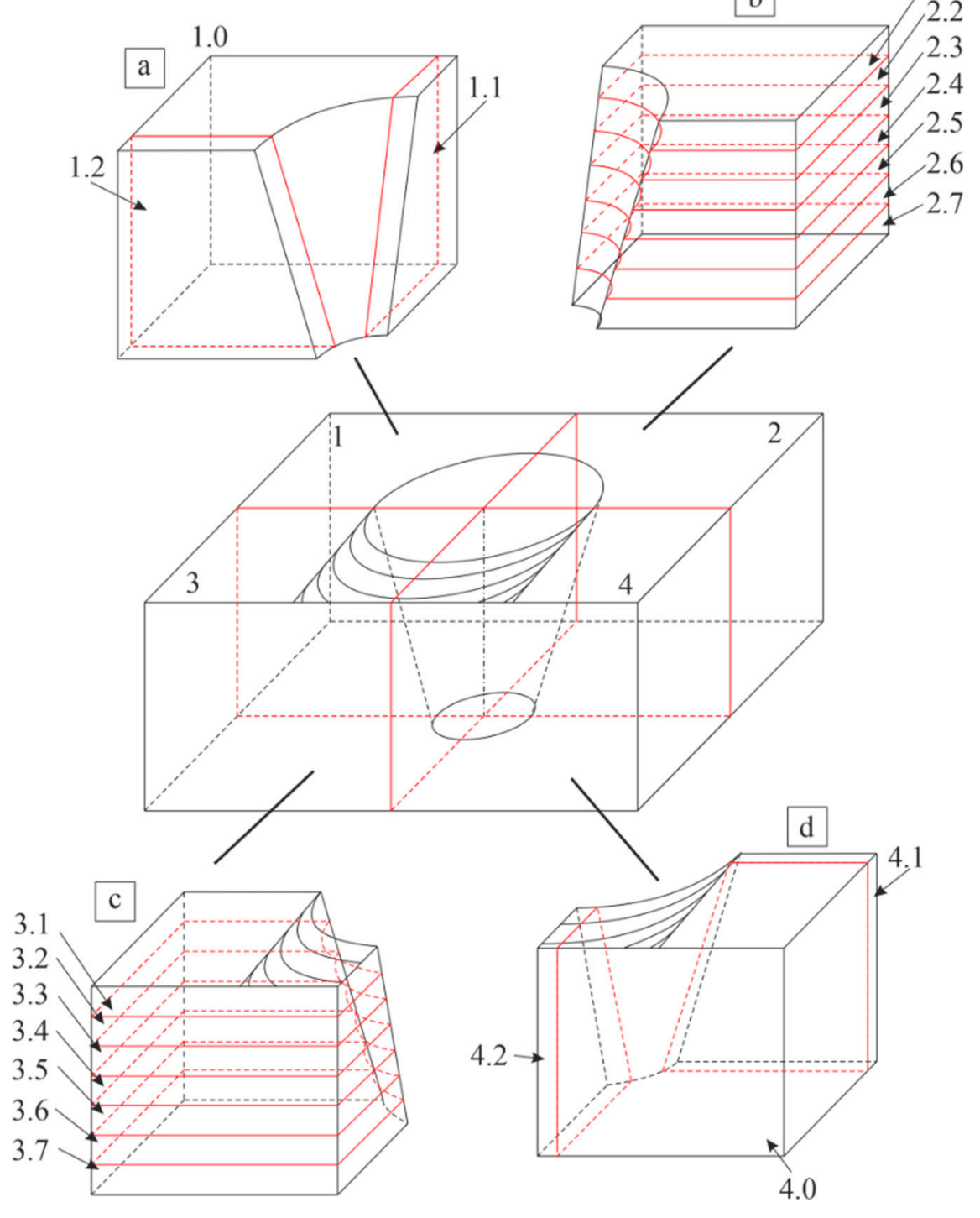

Figure 2. A diagram showing the sample cut-off scheme: (a) the leading edge of the exit hole on the retreating side (LE-RS), (b) the leading edge of the exit hole on the advancing side (LE-AS), (c) the trailing edge of the exit hole on the retreating side (TE-RS), (d) the trailing edge of the exit hole on the advancing side (TE-AS).

\section{Results}

\subsection{Stir Zone and Thermomechanically Affected Zone Macrostructures}

The transverse cross-sectional view in Figure 3 reveals the inhomogeneous macrostructure of the deep penetration FSW joint stir zone. The onset part of the joint (zone "B" in Figure 1) is characterized by a dense small nugget zone formed in the root part of the seam (Figure 3a,b), while "loose" metal with discontinuities (Figure 3a,b, defect 1 ) is formed in the top part. The FSW area behind the tool is characterized by the presence of a crack (Figure $3 a, b$, defect 2 ). 


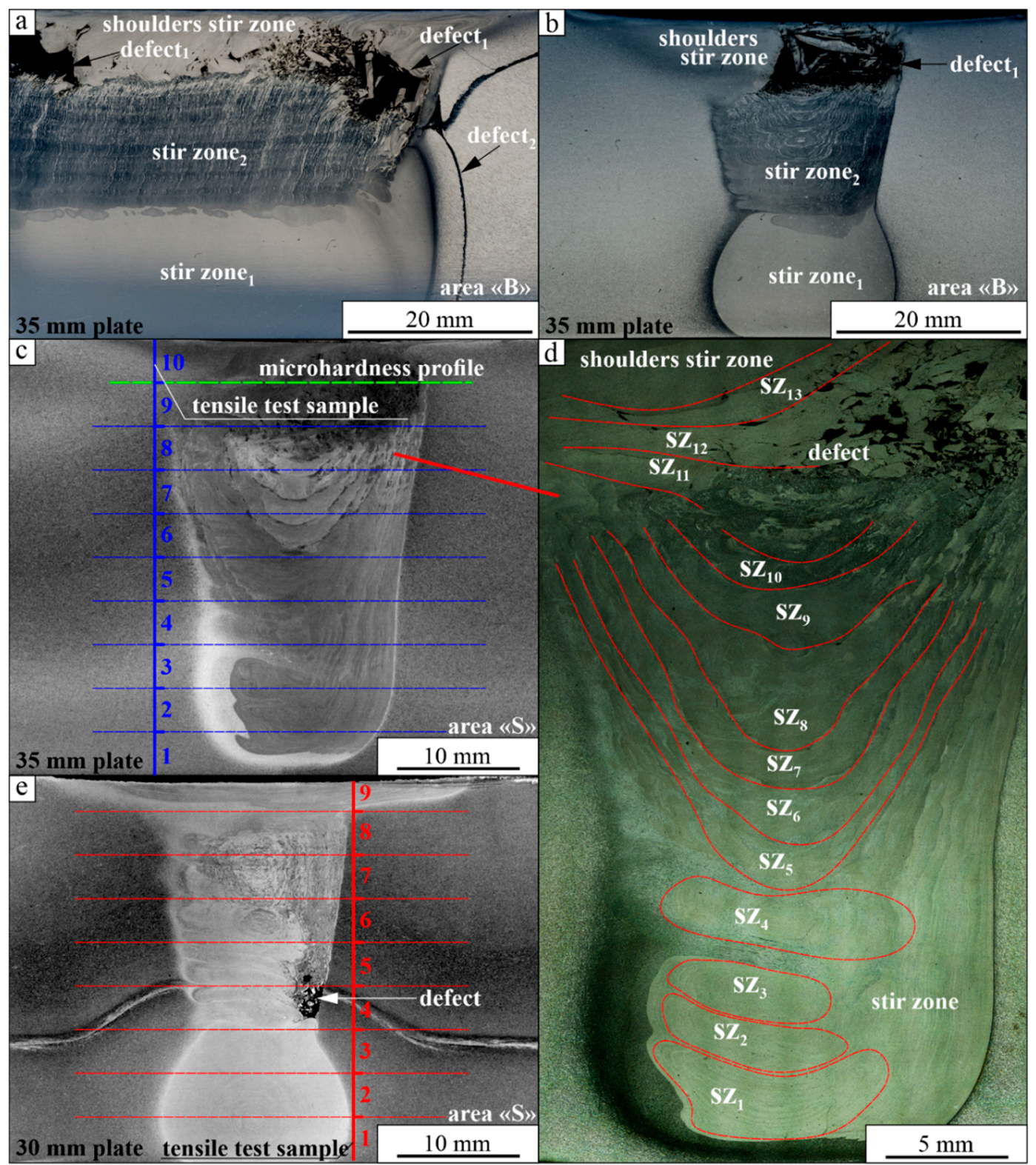

Figure 3. The macrostructures of the FSW joint on $35 \mathrm{~mm}$ thickness alloy sheet in section parallel to the joint line: (a) the cross section of zone B (b); the cross section of zone $S$ (c); the multi-nugget macrostructure of the stir zone (d); and a cross section view of the joint on the $30 \mathrm{~mm}$ thickness metal (e).

The steady welding zone " $\mathrm{S}$ " is characterized by another type of macrostructure, where numerous nugget structures are formed in the stir zone (SZ) instead of a single nugget (Figure 3c,d). These nugget structures are evidence of change in the metal flow compared to that of zone " $\mathrm{B}$ ". The top part of the stir zone obtained on the $35 \mathrm{~mm}$ thick sheet still contains pores and discontinuities.

This type of macrostructure is also typical for the FSW joint obtained on the $30 \mathrm{~mm}$ thick sheet (Figure 3e), with the exception of a wormhole defect formed in the half-height AS zone because this $30 \mathrm{~mm}$ thick sheet was made of two thinner ones.

The FSW tool exit zone $\mathrm{H}$ revealed the metal flow patterns formed by the tool around the exit hole. Figure 4 a shows the microstructure of sample 4.2 cut off the trailing part of the exit hole, as shown in Figure 2. The bottom metal shows a large and dense nugget (Figure $4 \mathrm{a}, \mathrm{SZ}_{1}$ ), above which a number of metal flow patterns $\left(\mathrm{SZ}_{2}-\mathrm{SZ}_{7}\right)$ can be seen. The "loosest" macrostructure is observed on the $\mathrm{SZ}_{8}$ pattern, which is formed by a shoulder-driven metal flow. 


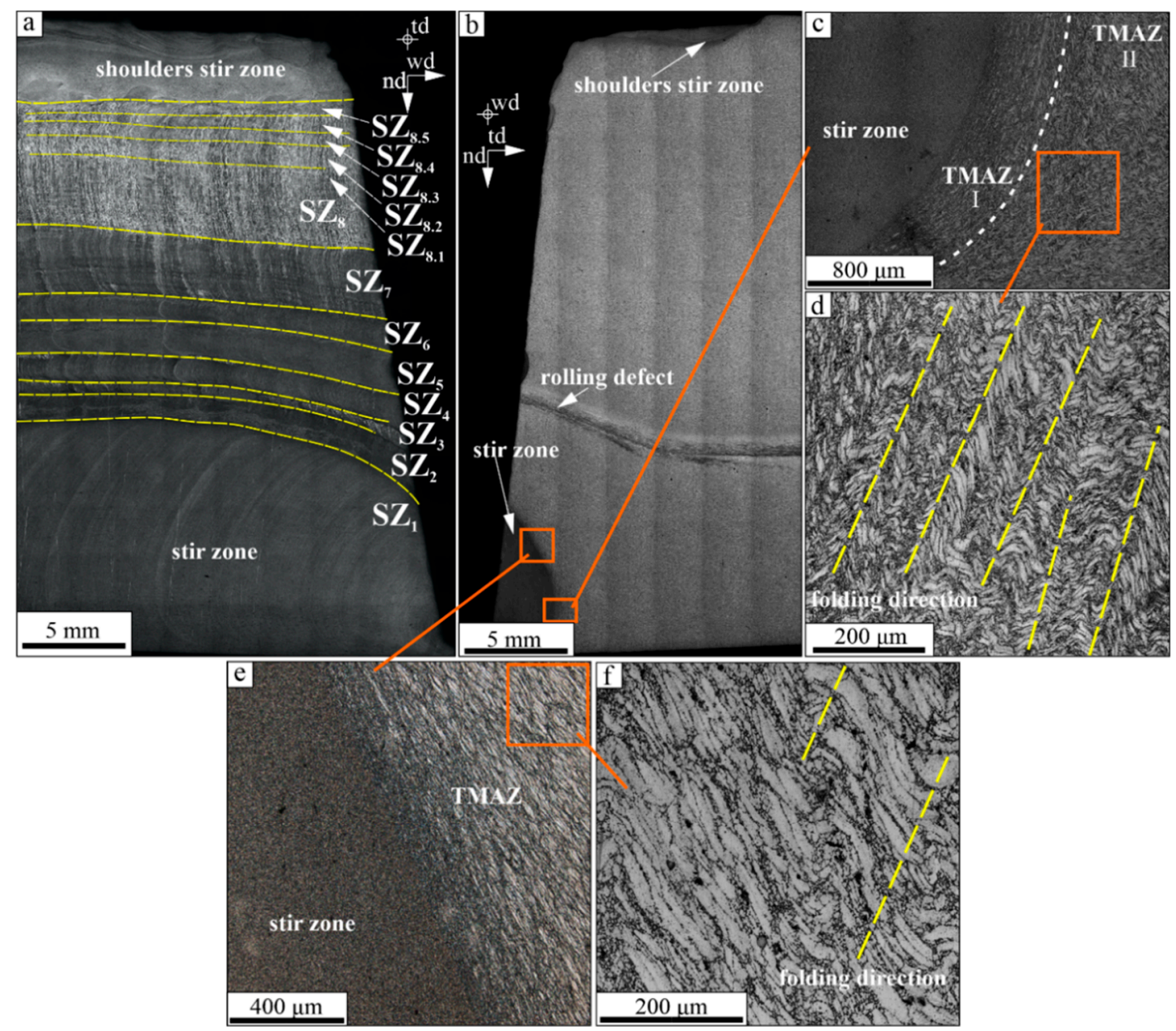

Figure 4. Macrostructures in the FSW tool exit zone as viewed from the plane parallel to the welding direction and perpendicular to the sheet's surface: (a) trailing part of the exit hole, sample 4.2; (b) the exit hole on the advancing side of the weld under different magnifications (c,e); kinked TMAZ grains in the top (f) and bottom (d) parts, respectively.

The macrostructure of the AS exit hole quadrant planar section (Figure $4 \mathrm{~b}$ ) (cut off as shown in in Figure 2, section 4.1) is represented by a difficult-to-see stir zone and a TMAZ that can be divided into the ultrafine grained TMAZ I in the vicinity of the SZ and TMAZ II, which features larger kinked grains located closer to the base metal (BM) (Figure $4 \mathrm{c}, \mathrm{d}$ ). Only a small portion of the SZ can be observed using this view. The rolling welding defect between the two sheets is also clearly seen here (Figure $4 \mathrm{~b}$ ). The TMAZ zone structures show orientation dependence with respect to the different exit hole quadrants. This is also true for such structural characteristics as grain size and grain shapes (Figure $4 \mathrm{c}, \mathrm{e})$.

Since the base metal hot-rolled grains were preferentially oriented with their longest axes along the rolling direction and their boundaries were pinned by the nanosized precipitates against continuous recrystallization, mechanical pressure in TMAZ II exerted from the SZ distorted their shapes. Distinct from the TMAZ I superfine grains, whose deformation at the SZ/TMAZ boundary was fully determined by the friction force, the TMAZ II grains oriented with their long axes along the pressure retained their sizes but instead experienced kinking. The alternating kinking band patterns can be delineated as shown in Figure $4 \mathrm{~d}$ and look similar to those generated with the shear banding mechanism. Those grains whose shorter axes coincide with the pressure direction were more resistant to kinking. Kinking is also more pronounced in the bottom parts of the TMAZ II where the FSW tool-induced metal flow pressure is higher. 
The planar section views in Figures 5-7 represent the structures formed at different distances below the metal surface. The structures formed close to the leading edge of the exit hole in sections 2.2-2.6, as well as those formed at the trailing edge of the exit hole in sections 3.2-3.6, are shown in Figures 5 and 6, respectively.

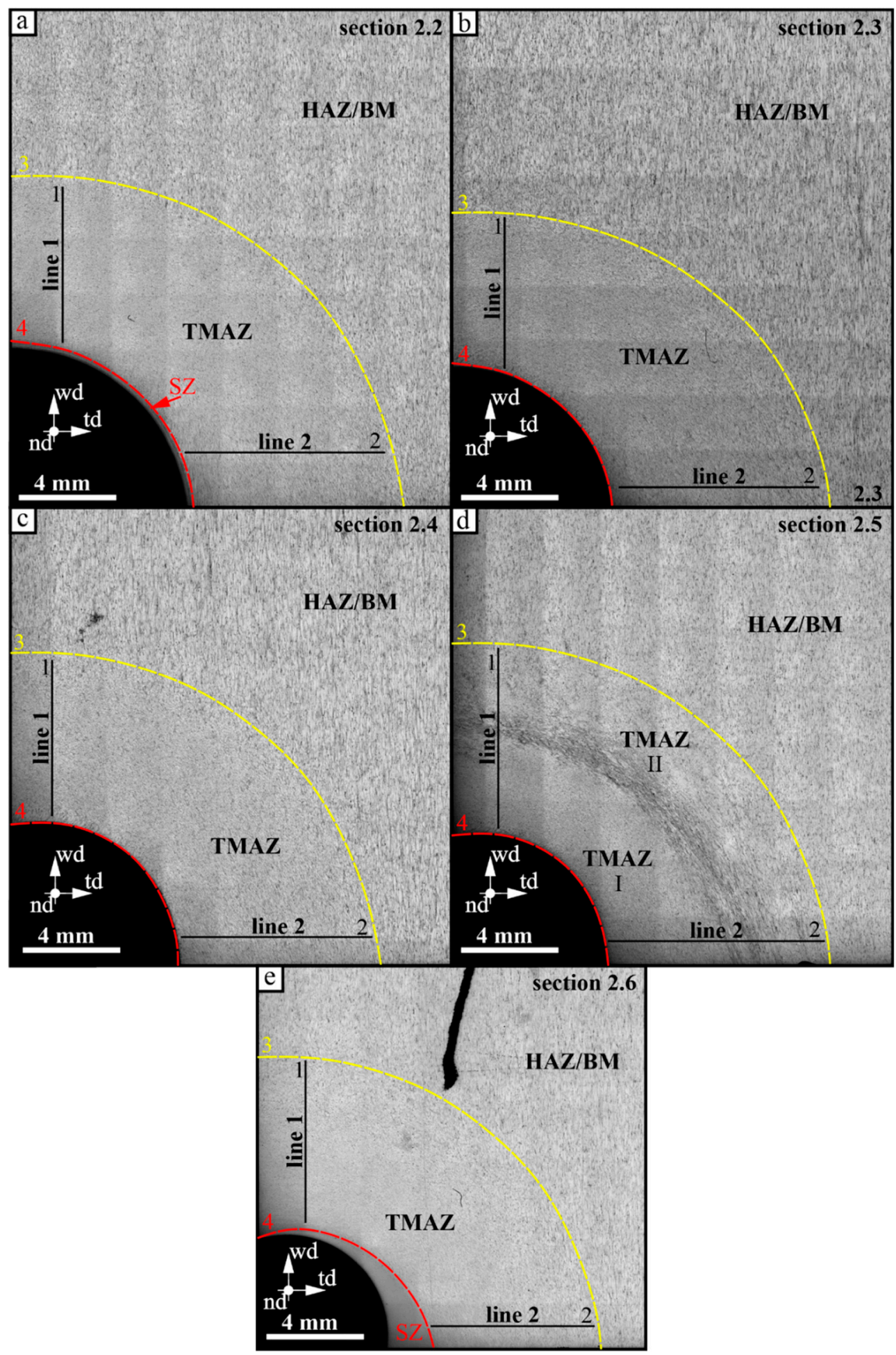

Figure 5. The microstructural evolution on stir zone (SZ), thermomechanically-affected zone (TMAZ), heat-affected zone (HAZ) and base metal (BM)microstructures near the exit hole leading edge on the advancing side (AS), as seen in plane sections 2.2 (a), 2.3 (b), 2.4 (c), 2.5 (d), and 2.6 (e) (Figure 2). 


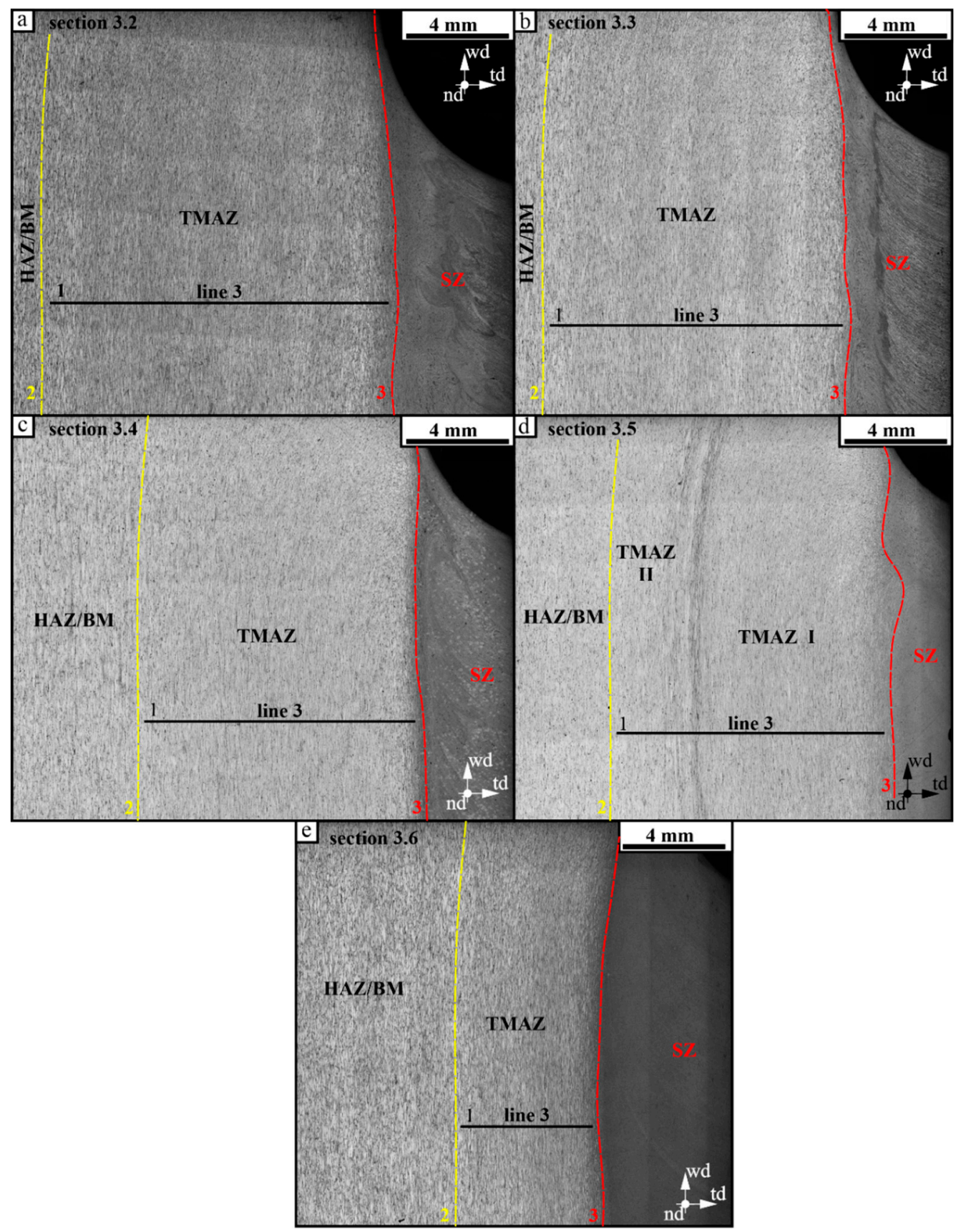

Figure 6. The alloy structures in the exit hole leading edge on the AS side, as viewed in sections 3.2 (a), $3.3(\mathbf{b}), 3.4(\mathbf{c}), 3.5$ (d) and $3.6(\mathbf{e})$ (Figure 2).

The leading AS edge planar sections 2.2 to 2.5 (see Figure 2) are represented by a very narrow stir zone (Figure 5a-d) but a wide TMAZ composed of both elongated and almost equiaxed grains, whose origin may be explained by horizontal plane sectioning of the kinked grains. The TMAZs are wide in sections 2.4-2.4 (Figure 5a-c), while those in section 2.5 (Figure 5d) demonstrate a narrow TMAZ that becomes wider again in section 2.6 (Figure 5 e).

The grain size in the TMAZ is gradually increased from the SZ/TMAZ to TMAZ/HAZ boundary (Figure 8).

When examining the structures and zones formed on the trailing edge of the hole in sections 3.2-3.6 (Figure 6), it can be noted that the TMAZ is wider in the RS trailing edge (TE-RS) (Figure 6) of the exit hole than the TMAZ in the leading edge AS part (LE-RS) (Figure 5). 


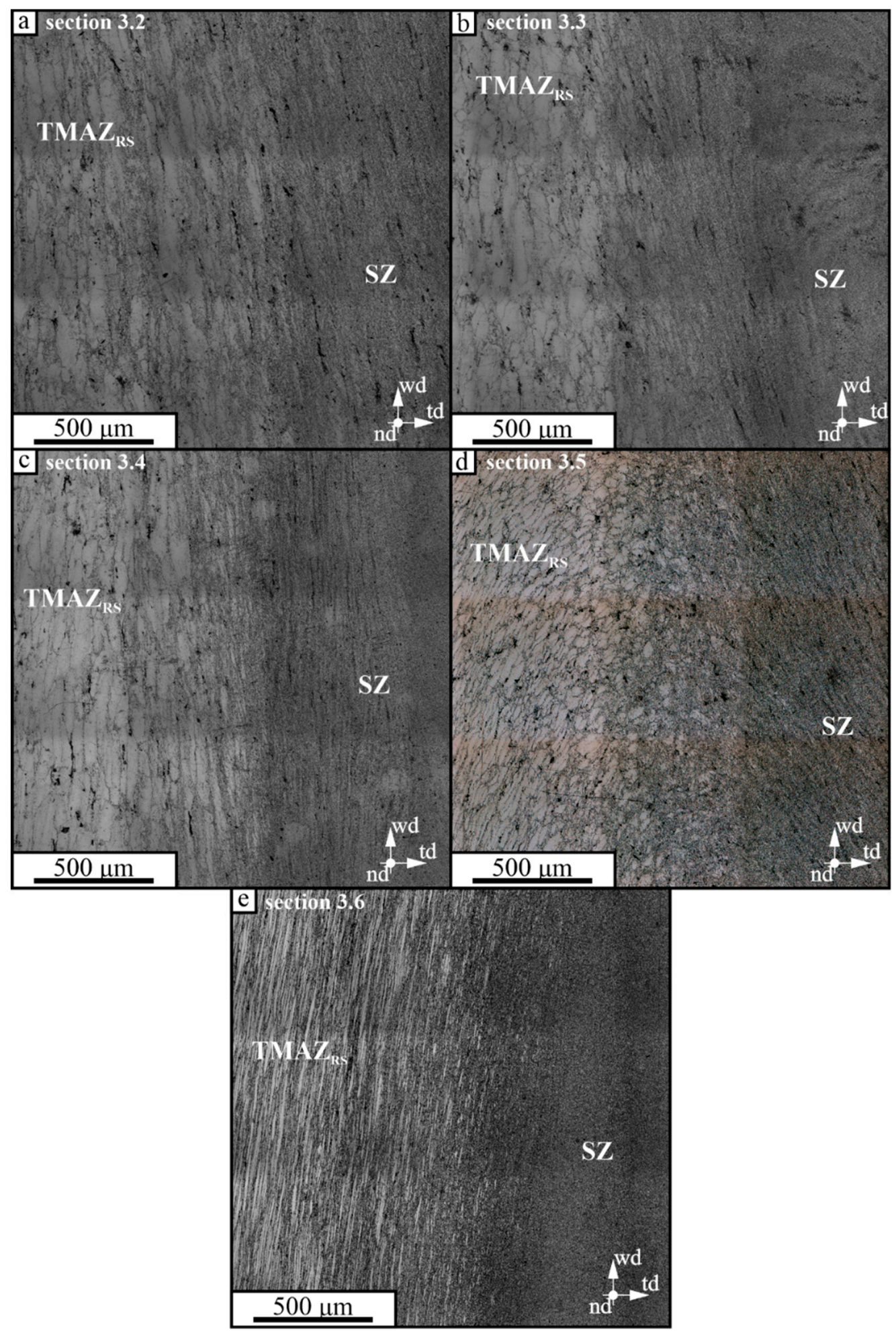

Figure 7. The TMAZ grain structures in planar sections 3.2 (a), 3.3 (b), 3.4 (c), 3.5 (d) and 3.6 (e), as viewed normal to the sheet plane.

These differences are clearly seen in Figure 7, where the TMAZ grain structures are shown at a higher magnification. sections 3.2 to 3.4 reveal moderately elongated grains whose length is about twice as much their width. sections 3.4 and 3.6, respectively, demonstrate almost equiaxed and extremely elongated thin grains. 

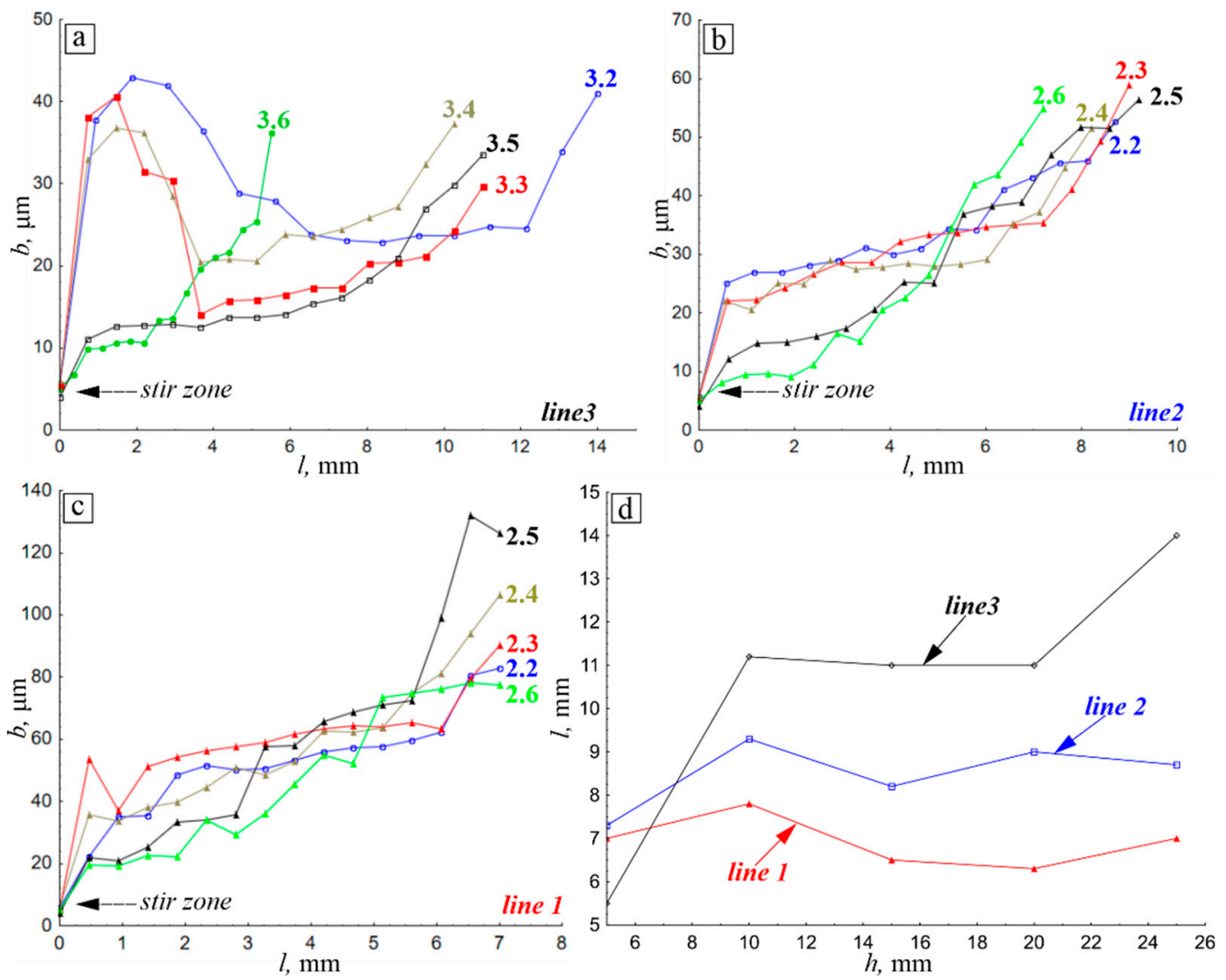

Figure 8. The TMAZ grain size distributions as measured along lines 3 (a), 2 (b), and 1 (c) (in Figures 5 and $6(\mathbf{a}, \mathbf{c}))$ and the dependence of the TMAZ size on the height of the $30 \mathrm{~mm}$ thick sample (d). The diagram labels are in accordance with those of the diagram in Figure 3.

\subsection{Stir Zone and Thermomechanically Affected Zone Microstructures}

The specifics of the TMAZ grain structure modification in the exit hole area are shown in Figure 8. Transversely to the SZ RS, along line 3 (shown in Figure 6), the change of the grain size from the stir zone to the heat-affected zone at different depths is determined by two main characteristic features. In samples from the upper part of the welded joint zone (sections 3.2, 3,3, and 3.4 in Figure 2), there is an initial rapid growth of grains with a subsequent drop and a further growth of the grain size, which becomes equal to the grain sizes of the heat-affected zone (HAZ) or the base metal. In samples from the bottom part of the joint (sections 3.5 and 3.6), the grains gradually grow from the stir zone to the heat-affected zone (Figure 8a). There is no grain growth near the stir zone. This feature indicates different deformation and recrystallization processes at different distances from the surface of the FSW-joint. At the leading edge of the tool exit hole on AS along line 2 (shown in Figure 5), the SZ-boundary material in sections 2.2, 2.3, and 2.4 is characterized by larger grains compared to those in sections 2.5 and 2.6 (Figure $8 \mathrm{~b}$ ). At a distance of more than $5 \mathrm{~mm}$ from the stir zone, the TMAZ grain size is leveled on all samples.

Along welding line 1 (Figure 5), the increase in the grain size from the stir zone to the heat-affected zone occurs gradually on all samples (Figure 8c). Significant differences are observed only for sections 2.5 and 2.4, far from the stir zone.

Unevenness in the size of the TMAZs can be observed both in different directions (for the welding axis) and at different distances below the weld surface (Figure 8d). It is expected that the smallest size of the TMAZ will be characteristic of the leading edge, where the TMAZ size changes smoothly and identically along line 1 and line 2 . In the trailing edge area on the retreating side and across the stir zone along line 3 , the size of the stir zone increases from the minimum in the bottom of the joint to the 
average in the central volume, with the maximum found in the shoulder-affected area. These changes show strain inhomogeneity in different areas of the joint.

The microstructures of the SZ zone in both joints are represented by recrystallized grains and coarse $\mathrm{Al}_{3} \mathrm{Sc}$ precipitates (Figure 9a,b). It can be seen from Figure 9c,d that the coarse incoherent particles cannot effectively pin the grain boundaries, so they continue migrating through the precipitates leaving chaotically distributed dislocations and dislocation loops.

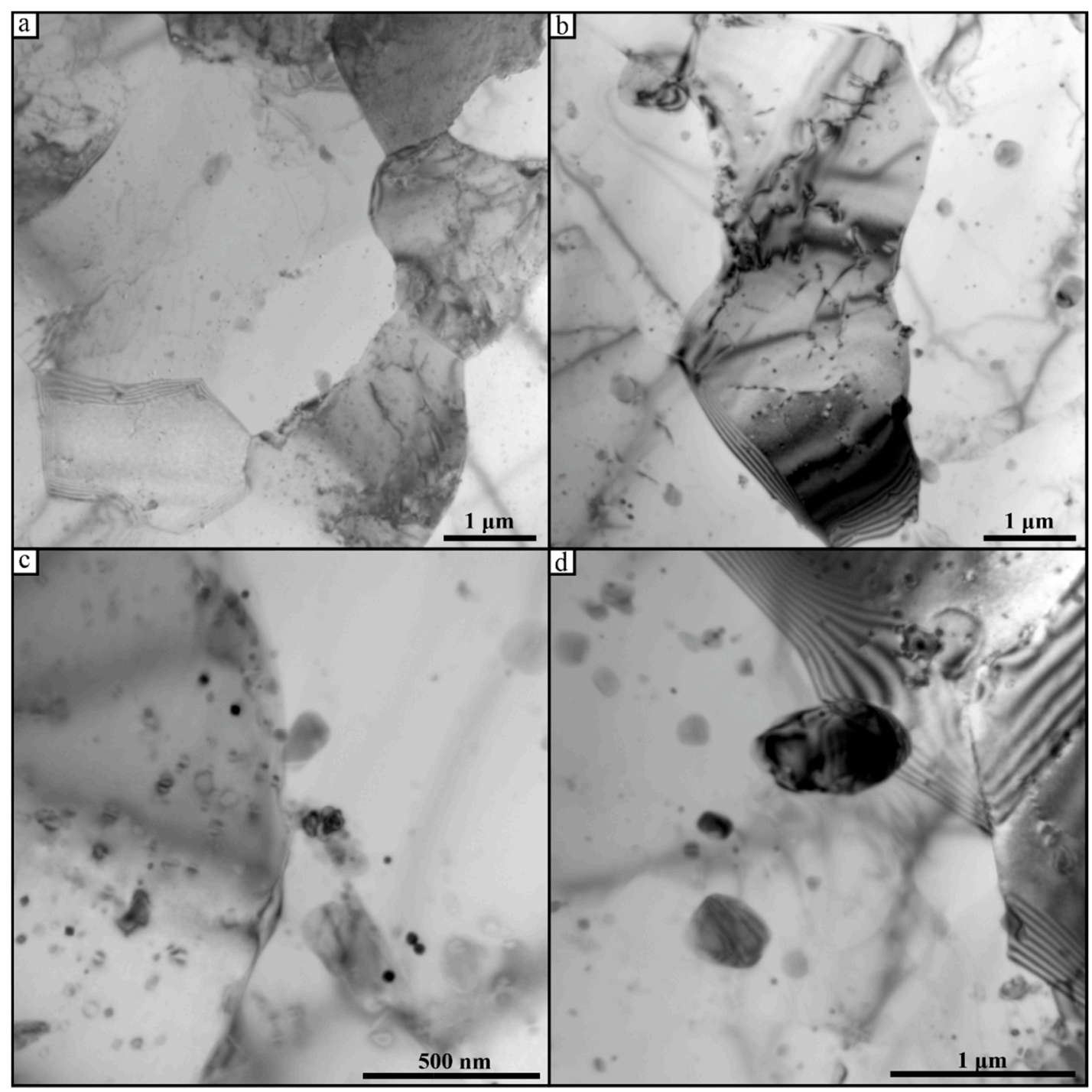

Figure 9. TEM images of the stir zone coarse precipitates, grains, and dislocation loops in $35 \mathrm{~mm}(\mathbf{a}, \mathbf{c})$ and $30 \mathrm{~mm}(\mathbf{b}, \mathbf{d})$ welds.

TEM images of the TMAZ microstructures in both FSW seams are characterized by the presence of numerous extinction contours inside the elongated and bent grains (Figure 10a, shown with arrows). The presence of several bend extinction contours inside an elongated grain is evidence of alternating sign flexural strain (corrugation). These corrugated grains are geometrically subdivided into shorter subgrains to accommodate the bending. Some of these subgrains are separated by high-angle boundaries from the neighboring subgrains (Figure 10b, shown with arrows). 


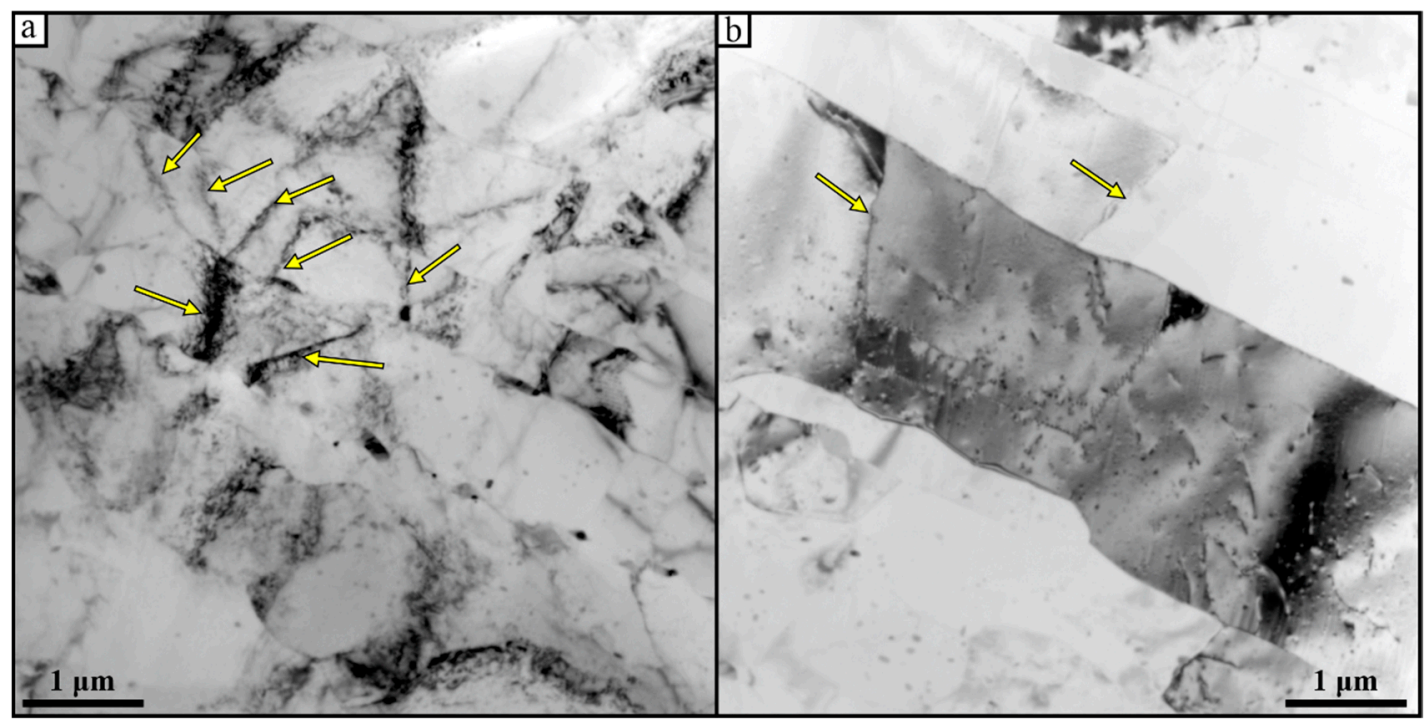

Figure 10. TEM images of the TMAZ structures in the $35 \mathrm{~mm}$ (a) and $30 \mathrm{~mm}(\mathbf{b})$ thickness seams.

\subsection{Mechanical Strength}

The results of the mechanical tests show that the welded metal has a strength close to that of the base metal (Figure 11a). The minimal tensile strength of 235-280 MPa was obtained when testing the samples cut off the top and bottom sections 1.1, 1.2, 1.9, and 1.10 (see Figure 3e). The samples cut off the central sections, with the exception of the section 1.7 sample, had a strength around 355-365 MPa.

Tests in the defect-free zone "S" (Figure 1) areas show that the ultimate tensile strength (UTS) of the specimens is about 350-390 MPa (Figure 11b). The exception is Specimen 2.10, cut from near the facing surface of the sample, whose UTS is about $305 \mathrm{MPa}$. The dependence of tensile strength on the distance from the weld root is shown in Figure 11c.

Testing of the welded samples shows their high defectiveness due to the formation of large discontinuity in the weld, which is detrimental to the metal's mechanical properties (Figure 11c,d). Samples from the defect-free areas have strength properties at the level of equivalent samples from $35 \mathrm{~mm}$ thick welded plates at a level of 400-405 MPa. In the presence of defects, this strength is very low (even close to zero). The difference between zone "S" and zone "B" (Figure 1) is seen in the diagrams. Only one sample cut from the center zone showed a strength close to zero, while about one third of them cut from zone "B" had similar results.

When comparing the mechanical properties in the cross sections of materials of both thicknesses, the defect localized in the structure becomes clearly distinguished (Figure 11e,f). For joints made of $35 \mathrm{~mm}$-thick plates, the poor strength shown on samples from the upper part is typical (Figure 11e). For samples made of $30 \mathrm{~mm}$-thick plates, the strength loss is typical for samples from the central part of the joint (Figure 11f). It should be noted that, generally, samples demonstrate rather low mechanical properties in comparison with that of the base metal, which could be caused by over-ageing of the SZ material during welding. This process is characterized by accelerated precipitation of the particles from the solid solution, making the particles lose their coherence with the matrix and thus impairing the joint mechanical characteristics. At the same time, the mechanical properties of the base metal also have a significant heterogeneity when testing samples cut off along and across the rolling direction (Figure 11g). In this case, the samples cut along the rolling direction have a slightly higher strength and less ductility than those cut across the rolling direction. 

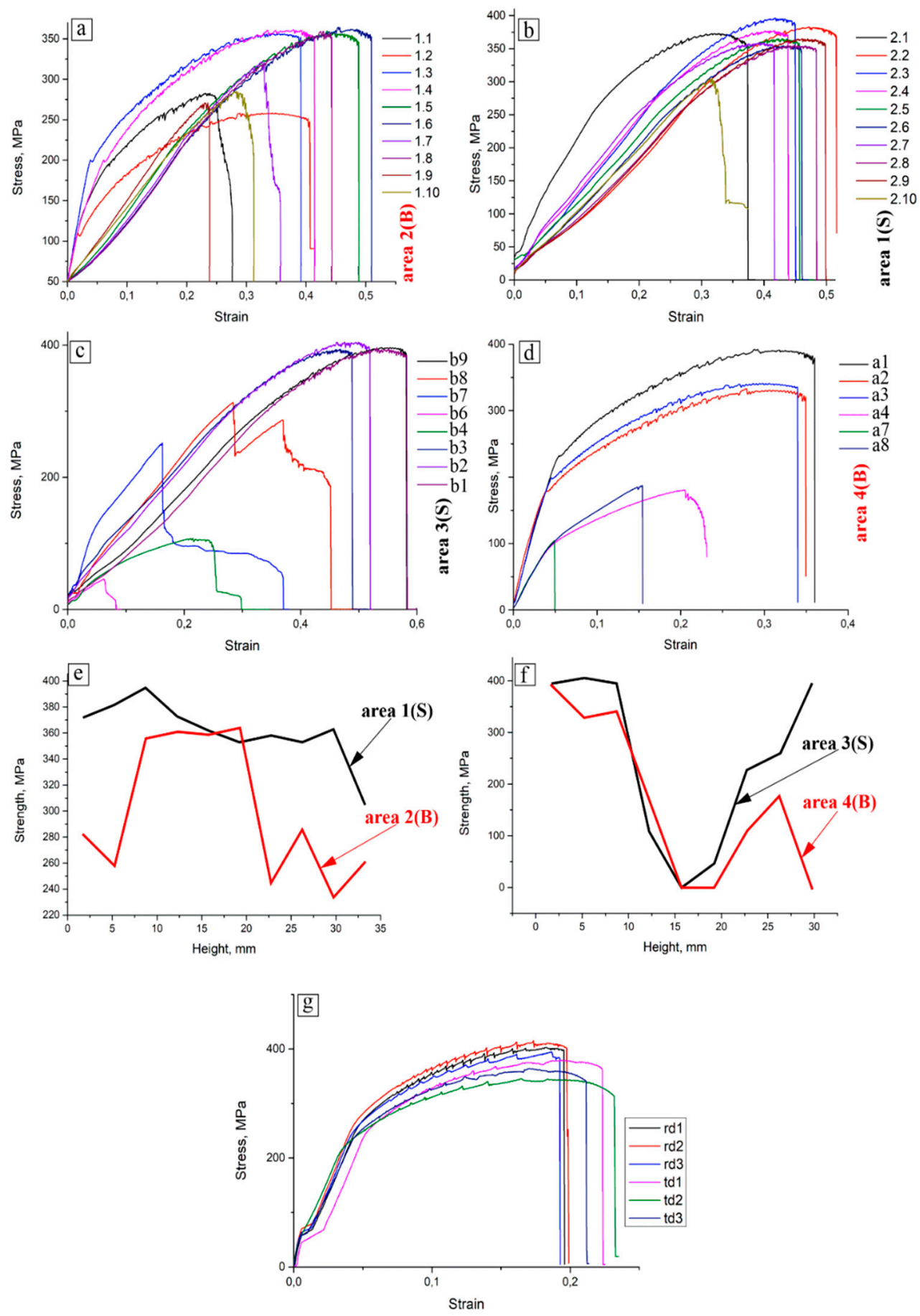

Figure 11. Mechanical properties of specimens cut across the weld at different distances from the weld root for $35 \mathrm{~mm}$-thick $(\mathbf{a}, \mathbf{b})$ and $30 \mathrm{~mm}$-thick (c,d) plates, the dependence of the mechanical properties on the distance from the weld root for $35 \mathrm{~mm}$-thick (e) and $30 \mathrm{~mm}$-thick (f) plates in zones " $\mathrm{B}$ " and " $\mathrm{S}$ " (see Figure 1), and the test diagrams of the base metal tested along and across the rolling direction (g).

The discontinuous yielding effect, strongly pronounced during the testing of the base metal specimens (Figure 11g), is eliminated during the testing of the FSW joined samples. During the deformation of specimens along and across the welding axis, the most pronounced manifestation of the Portevin Le Chatelier effect is observed in cases where the tensile axis coincided with the welding axis. This leads to high amplitude serrations under the tensile loading. In samples of the weld material, the phenomenon of discontinuous yielding was observed practically on all specimens cut from the 
defect-free zones as well as on a small part of the defective ones (Figure 11a-d). Some specimens demonstrated deformation behavior similar to that of the base metal ones tested along the rolling direction, and others showed the same with specimens tested across the rolling direction. For example, curves a1, a2, and a3, shown in Figure 11d, demonstrate similar changes in strain to those in diagrams of the specimens cut along the rolling direction rd1-rd3, while curves 2.1 and 2.3 are similar to those in diagrams of the specimens cut along the transverse direction td1-td3. The main difference between the above groups of specimens is their differently pronounced stress changes during deformation. In this case, the strength of the base metal in the tensile test along the rolling direction is $405 \mathrm{MPa}$, which coincides with the strength of the $30 \mathrm{~mm}$-thick joint specimens in the transverse direction of $365 \mathrm{MPa}$, which is close to the strength of the defect-free specimens of the $35 \mathrm{~mm}$-thick joint.

The microhardness profiles obtained from both joints demonstrate the reduced microhardness numbers of the stir zone (Figure 12) compared to those of base metal. Such a finding is typical for heat treatable aluminum alloys because this zone is usually over-aged in FSW such that the precipitates lose their coherence, and dispersion hardening becomes ineffective. No extra hardening was noted in the heat-affected zone, which may be explained by the thermal stability of both grains and precipitates in this zone.

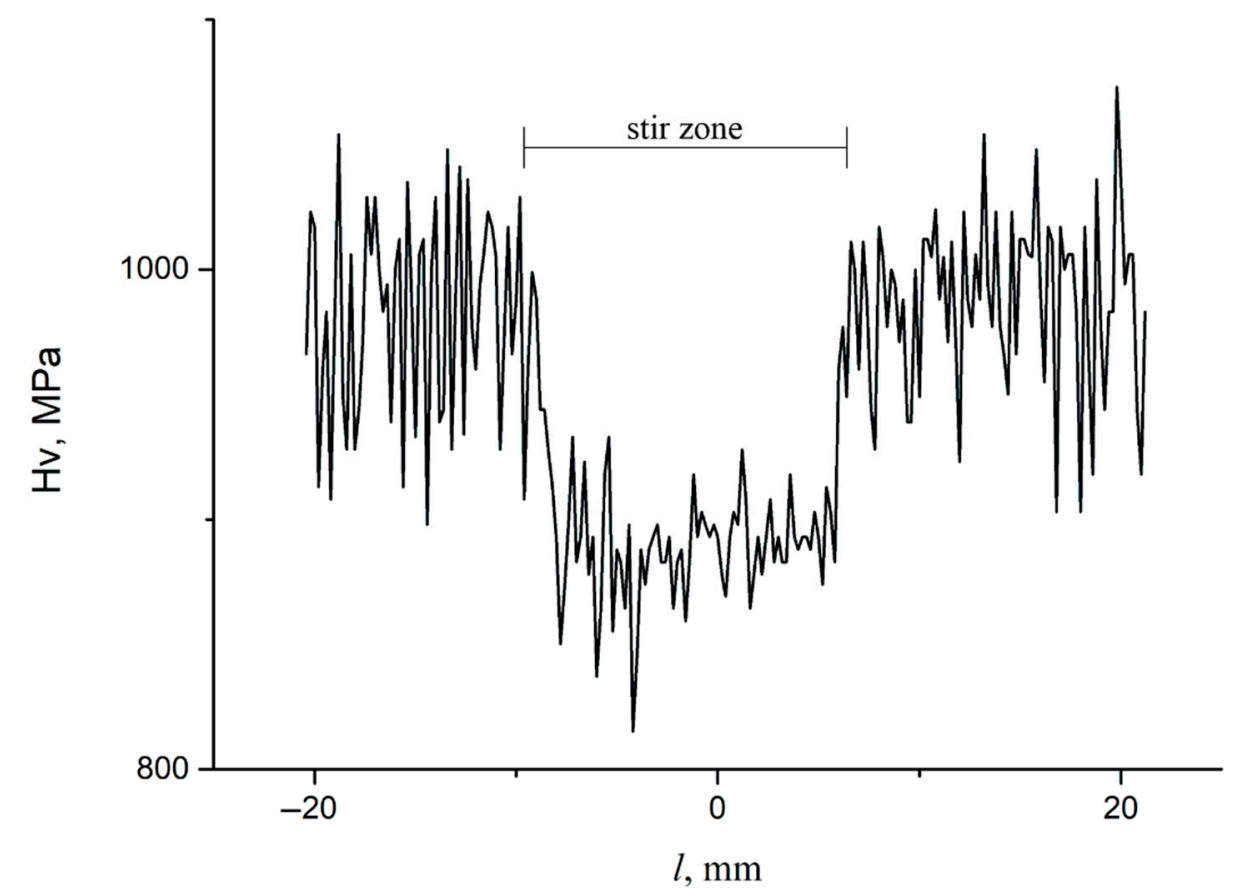

Figure 12. The microhardness profile across the FSW joint at $5 \mathrm{~mm}$ below the surface on $35 \mathrm{~mm}$ thickness metal.

\subsection{Metal Transfer}

The macrographs in Figures 13 and 14 show grain refining in the base metal via friction from the rotating FSW tool. It was suggested earlier [20] that metal transfer in FSW may be performed in a layer-by-layer manner when the grain-refined and plasticized metal layer first sticks to the FSW tool surface and is then transferred to the zone behind the tool and deposited there on a previously deposited layer. The stop-action technique allows one to observe plasticized metal layers, which are separated from the bulk of the metal on the advancing side of the hole (Figure 13), transferred to the retreating side (Figure 14), and finally deposited on the previously transferred and bonded layers. 


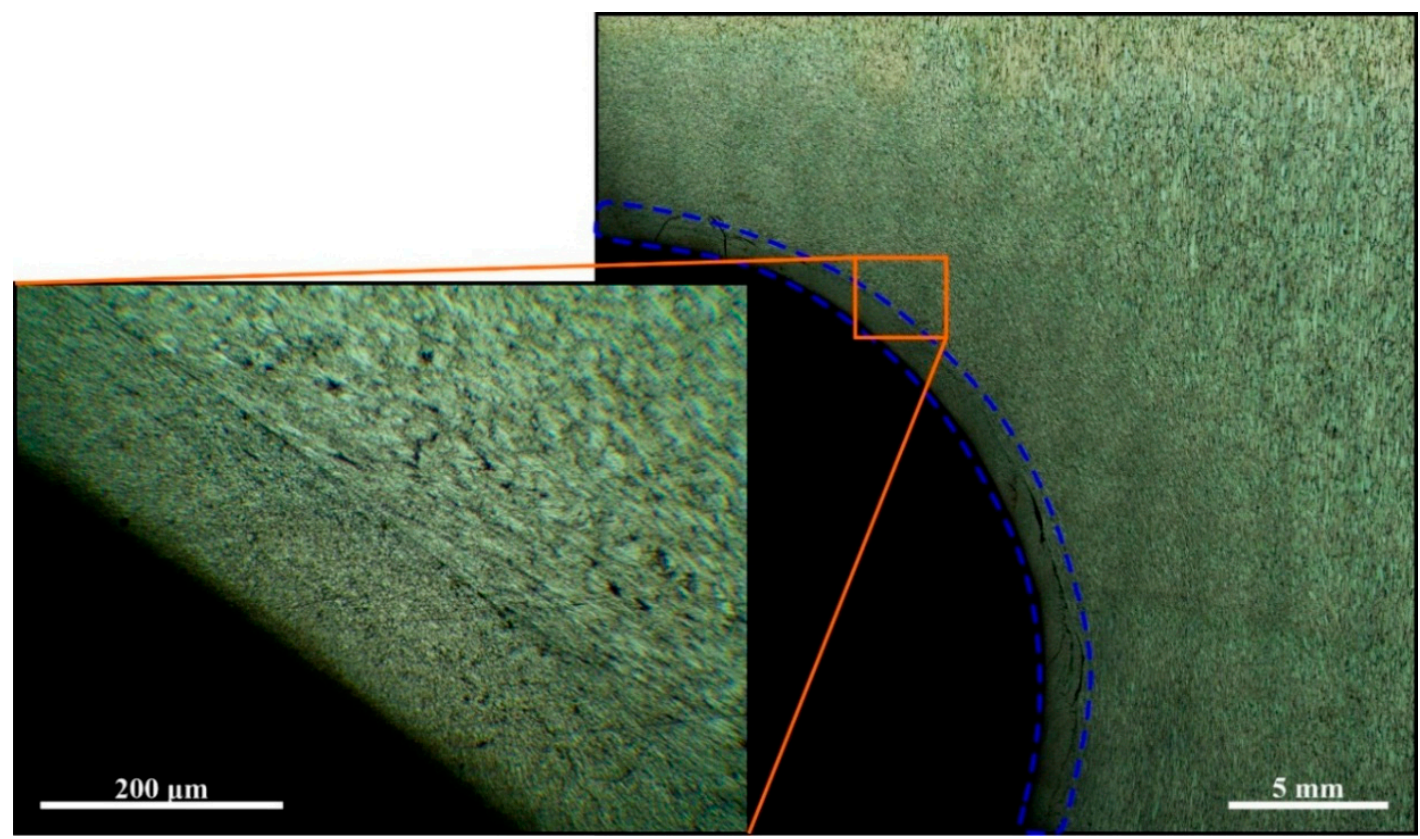

Figure 13. Optical images of the microstructures formed in the FSW tool exit hole metal leading edge metal (section 2.2 in Figure 2). Blue dotted line contour denotes the transfer layer area.

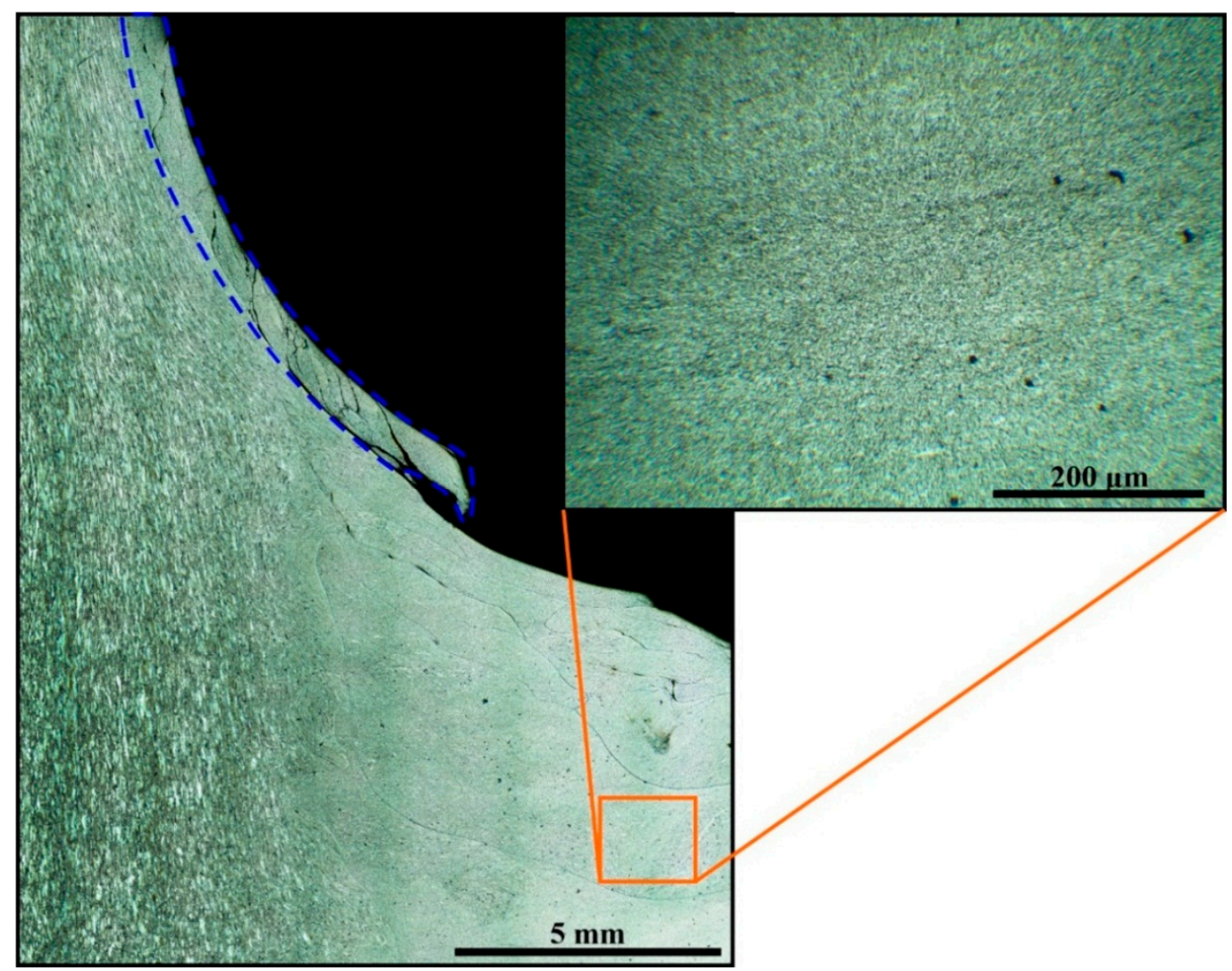

Figure 14. Optical images of the microstructures formed in the FSW tool exit hole metal trailing edge metal (section 3.2 in Figure 2). The blue dotted line contour denotes the transfer layer area.

SEM BSE images allow one to distinguish by contrast the intermetallic precipitates of solid solution grains (Figure 15). The majority of these coarse precipitates look like streaks oriented along 
the rolling direction (as well as tool travel speed) and are clearly seen in the base metal, while fewer are distributed chaotically.

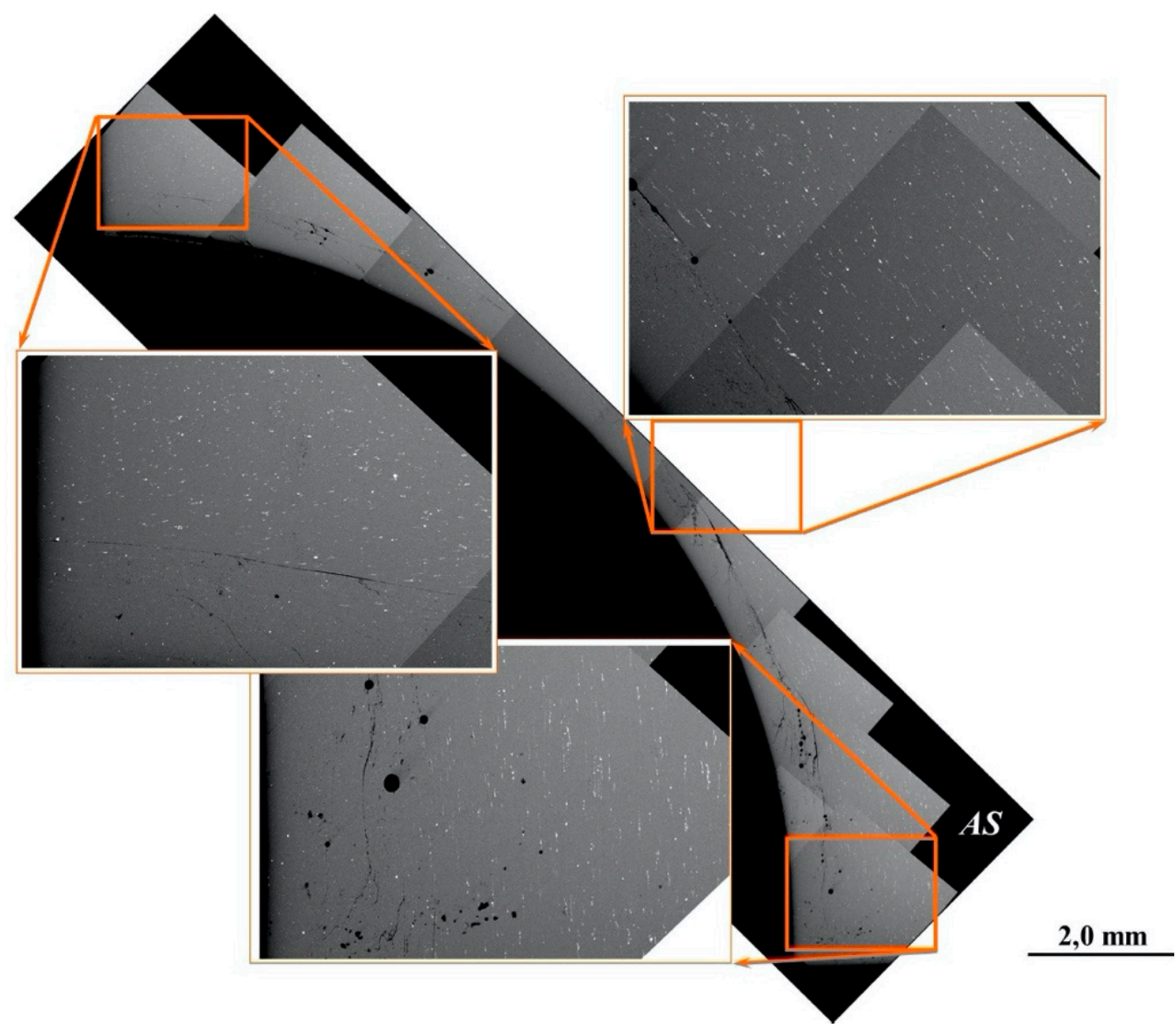

Figure 15. SEM BSE composite image of the metal and precipitates in the FSW tool exit hole leading edge metal (section 2.2 in Figure 2).

The friction force induced deformation not only distorts the grains but also changes their orientation, which can be observed by the orientation of the precipitate streaks (Figure 15).

Completely recrystallized metal is observed in a thin $0.5-0.6 \mathrm{~mm}$ layer, which was stuck to the FSW tool and thereby transferred in a spiral bottom-to-surface trajectory.

\section{Discussion}

The stir zone formation in high thickness materials may occur in a very complex multiflow manner so that a number of vortex structures with different configurations forms there, partially due to the low pressure in the welding zone. As a result, a welded joint has, in addition to structural irregularities, significant differences in its mechanical properties with respect to the distance below the top surface. Despite the presence of structural irregularities, it is possible to accurately characterize the process of the welded joint formation in the tool pin stir zone (excluding the area of shoulders influence). As described above, the direct material transfer by the tool is predefined by the primary subdivision of the base metal grains through severe plastic deformation with the formation of a wide thermomechanically affected zone (Figure 5). The grain size is expected to increase with distance from the stir zone to the heat-affected zone (Figure 8). The different widths of the TMAZ at different levels of the weld indicates that the process of grain subdivision and, consequently, the formation of the material transfer layer (Figures 14 and 15) occurs with a different intensity depending on the distance below the top surface. This ensures that the stir zone consists of several nuggets and makes the material transfer frequency potentially differ from level to level. This irregularity in the adhesive 
interaction also likely affects the mechanical characteristics. However, the peculiarities of the formation of structures at each of the studied weld levels demonstrate that the welded joint formation in the tool pin stir zone occurs via the same mechanism.

The results obtained in this work, as well as those obtained earlier, suggest that FSW seam formation occurs according to the scheme shown in Figure 16.

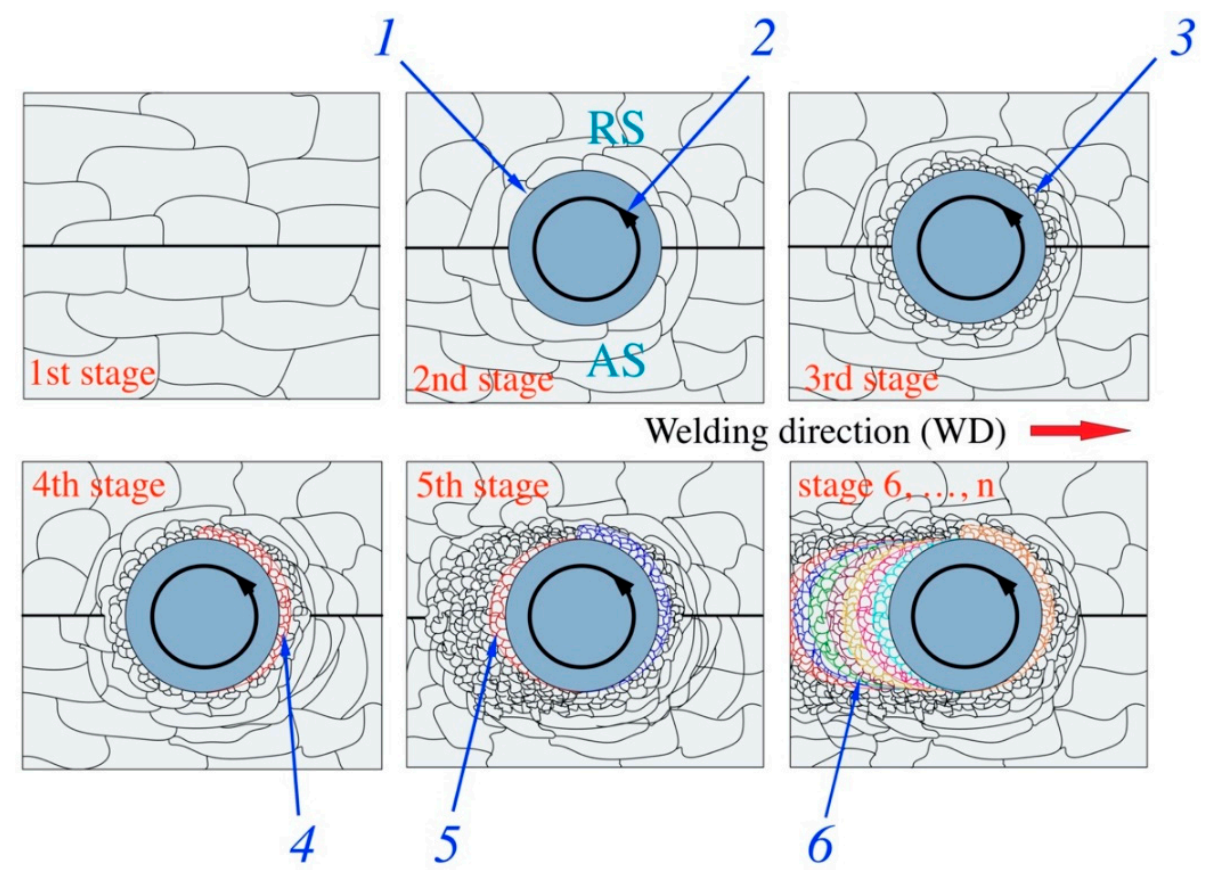

Figure 16. Schematic diagram to illustrate the adhesion-assisted transfer of metal with the FSW pin. 1-tool, 2-rotation direction, 3-primary grain subdivision, 4-formation of transfer layer, 5-reverse transfer (deposition), 6-successive layer-by-layer metal transfer and deposition.

After plunging the FSW tool into a metal, the tool starts travelling along the joint line. The plasticized and grain refined metal layer is transferred by the rotating tool to the trailing zone where it is detached from the tool and sticks back to the hot metal deposited. This cycle is repeated again and again to form the welded seam. The transferred layer thickness is determined by the temperature and shear stress/strain gradients exerted from the tool into the base metal. This model was inferred from numerous experiments on unlubricated and adhesion controlled sliding friction when direct and reversed metal transfer occurs between the contacting bodies [20-22].

This discontinuous transfer mechanism is responsible for the formation of inhomogeneous grain structures, SZ nuggets, and the TMAZ. An overly strong adhesion of the plasticized metal to the FSW tool may have detrimental effects on the stirring and metal flow efficiency. The transferred portion of metal may not detach from the tool surface and thus be involved in the next cycle, thus breaking the regularity of transfer and forming additional metal flows, which can then provide the final multi-nugget pattern shown in this work in Figure 3c,d. This is especially likely in FSW on thick metal sheets with high pressure and tool travel resistance.

On the other hand, overly weak adhesion would not allow the metal to form a welded joint at all. Therefore, the adhesion of the metal to the tool is an important factor in metal transfer, which has never been considered in modeling. It is known, for example, that it is possible to obtain an FSW seam using an absolutely smooth FSW pin surface $[23,24]$ and that it is the adhesion that works here to help transfer the metal.

Our results show that the SZ metal precipitates are not coherent with the Al-Mg matrix; thus, grain structure recrystallization is not stopped and continues by means of grain boundary migration and diffusion-controlled dissolution of the incoherent precipitates, leading to numerous dislocation loops 
forming in the metal. It is known that the dislocation loops can appear by a vacancy condensation mechanism in diffusion on the grain boundaries. It seems that the coarse precipitates almost have no pinning effect of the grain boundaries so that grains may grow as large as several micrometers. Severe deformation and heating during FSW facilitates strain dissolution of the initial precipitates that, consequently, have to precipitate again. Intense stirring in the SZ dissolves them again and again until stirring is stopped and the metal comes to rest. This is where precipitation overtakes dissolution, and precipitates grow very quickly on the defective structure. That is why the coarsest precipitates are found in the TMAZ (Figure 3), where the strain is low and some particles are hiding there and thus avoid the strain dissolution. In addition, Figure 8 a shows that some grain growth can occur in the vicinity of the SZ/TMAZ boundary. This finding can be explained by the same reason, i.e., that the coarse incoherent precipitates are formed in the TMAZ and allow the grains to grow. Nevertheless, even if the precipitates are semicoherent, they may still retain some pinning effects on the grain boundaries.

The TMAZ zone is characterized by kinked grains (Figure 4d), which are the results of deformation under the pressure exerted by the FSW tool. A similar effect was observed under compression deformation of the Al-Mg-Sc alloy (AA5024) at $523 \mathrm{~K}$ [25]. TEM mages show that these kinked grains are composed of even smaller subgrains with high-angle boundaries (Figure 13) that are plausibly formed by microshears in the band-like grains, according to the scheme proposed by Belyakov et al. [26]. Another possible mechanism could be geometrical recrystallization [27], which is considered to be a type of continuous recrystallization. It was reported [28] that continuous recrystallization is inherent with the Al-Mg-Sc-Zr alloys.

\section{Conclusions}

As a result of the study, it was found that the stir zone of FSW joints on heavy gauge Al-Mg-Sc-Zr alloy sheets is a complexly structured zone with the presence of several basic structural elements. At the beginning of the welded joint, there is a nugget with an onion ring structure of a small size, and a highly defective area is located closer to the weld top surface. In the middle and end of the $35 \mathrm{~mm}$-thick joint, there is a stir zone with a complex structure that consists of a large number of vortex or turbulent material flows formed by its movement along the tool contour. In the $30 \mathrm{~mm}$-thick sample, a stir zone with a small nugget was formed over the entire length of the joint.

In samples of both thicknesses, defects can occur throughout the entire weld length and reduce the strength of the joint area to almost zero. The macro-defect formation localization is possible both in the lower third of the thickness in the advancing side of the weld and in the upper part in the stir zone in the shoulder effect area. Alternatively, it can be located on the border of the stir zone in the shoulder-driven area and in the pin-driven area. In the zone of defect formation, the strength properties are about 235-280 MPa for $35 \mathrm{~mm}$-thick plates and for $30 \mathrm{~mm}$-thick plates in the defect areas, the strength decreases until reaching zero, which might be caused by different types of formed defects. The mechanical properties of the defect-free material are thus at a sufficiently high level. Specimens from the defect-free areas of the $30 \mathrm{~mm}$-thick joints have strength properties around 400-405 MPa, while specimens from $35 \mathrm{~mm}$-thick welded joints have a lower strength of about 350-390 MPa. The strength of the base metal during the tensile test along the rolling direction is $405 \mathrm{MPa}$, and in the transverse direction it is $365 \mathrm{MPa}$. In terms of strength and discontinuous yielding effect implementation, specimens from the $30 \mathrm{~mm}$-thick plates were closer to the base metal tested along the rolling direction, while specimens from the $35 \mathrm{~mm}$-thick plates were closer to the material tested across the rolling direction.

The structure of welded joints is formed by the successive layer-by-layer transfer of a material by means of adhesive interaction. Due to the high thickness of the plates to be welded, the process of joint formation becomes more complicated, and the layer transferred by the tool is divided into separate sections with the presence of an upward motion component along with the motion around the tool. The high thickness of the Al-Mg-Sc-Zr alloy plates being welded might affect the plastic deformation 
process during the FSW so that metal flow was rearranged into separate small vortex zones, along with the formation of complex material flows along the tool contour and, as a result of the above, the formation of a multi-nugget stir zone with a complex structure.

Author Contributions: Conceptualization, writing-original draft preparation, methodology, investigation, visualization, T.K. and A.C.; formal analysis, writing-review and editing K.K.; investigation, S.F.; project administration, supervision, E.K.; conceptualization, S.T. All authors have read and agreed to the published version of the manuscript.

Funding: The work was performed according to the government research assignment for ISPMS SB RAS, project No. III.23.2.4.

Conflicts of Interest: The authors declare no conflict of interest.

\section{References}

1. Gureeva, M.A.; Grushko, O.E. Aluminum Alloys in the Modern Transportation Manufacturing and Education; Moscow State Industrial University (MSIU): Astrakhan, Russia, 2009; Volume 3, pp. $27-41$.

2. Filatov, Y.A.; Yelagin, V.I.; Zakharov, V.V. New Al-Mg-Sc alloys. Mater. Sci. Eng. A 2000, 280, 97-101. [CrossRef]

3. Deng, Y.; Zhang, G.; Yang, Z.; Xu, G. Microstructure characteristics and mechanical properties of new aerospace $\mathrm{Al}-\mathrm{Mg}-\mathrm{Mn}$ alloys with $\mathrm{Al}_{3}\left(\mathrm{Sc}_{1-\mathrm{x}} \mathrm{Zr}_{\mathrm{x}}\right)$ or $\mathrm{Al}_{3}\left(\mathrm{Er}_{1-\mathrm{x}} \mathrm{Zr}_{\mathrm{x}}\right)$ nanoparticles. Mater. Charact. 2019, 153, 79-91. [CrossRef]

4. Yang, W.; Yan, D.; Rong, L. The separation of recrystallization and precipitation processes in a cold-rolled Al-Mg-Sc solid solution. Scr. Mater. 2013, 68, 587-590. [CrossRef]

5. Heinz, A.; Haszler, A.; Keidel, C.; Moldenhauer, S.; Benedictus, R.; Miller, W.S. Recent development in aluminium alloys for aerospace applications. Mater. Sci. Eng. A 2000, 280, 102-107. [CrossRef]

6. Kumar, N.; Mishra, R.S. Thermal stability of friction stir processed ultrafine grained Al-Mg-Sc alloy. Mater. Charact. 2012, 74, 1-10. [CrossRef]

7. Nikulin, I.; Kipelova, A.; Malopheyev, S.; Kaibyshev, R. Effect of second phase particles on grain refinement during equal-channel angular pressing of an Al-Mg-Mn alloy. Acta Mater. 2012, 60, 487-497. [CrossRef]

8. Tuan, N.Q.; Pinto, A.M.P.; Puga, H.; Rocha, L.A.; Barbosa, J. Effects of substituting ytterbium for scandium on the microstructure and age-hardening behaviour of Al-Sc alloy. Mater. Sci. Eng. A 2014, 601, 70-77. [CrossRef]

9. Meng, Y.; Zhao, Z.; Cui, J. Effect of minor $\mathrm{Zr}$ and Sc on microstructures and mechanical properties of Al-Mg-Si-Cu-Cr-V alloys. T. Nonferr. Metal. Soc. 2013, 23, 1882-1889. [CrossRef]

10. Deng, Y.; Peng, B.; Xu, G.; Pan, Q.; Yin, Z.; Ye, R.; Wang, Y.; Lu, L. Effects of Sc and Zr on mechanical property and microstructure of tungsten inert gas and friction stir welded aerospace high strength $\mathrm{Al}-\mathrm{Zn}-\mathrm{Mg}$ alloys. Mater. Sci. Eng. A 2015, 639, 500-513. [CrossRef]

11. Malopheyev, S.; Kulitskiy, V.; Mironov, S.; Zhemchuzhnikova, D.; Kaibyshev, R. Friction stir welding of an Al-Mg-Sc-Zr alloy in as-fabricated and work-hardened conditions. Mater. Sci. Eng. A 2014, 600, 159-170. [CrossRef]

12. Liu, F.C.; Ma, Z.Y. Achieving exceptionally high superplasticity at high strain rates in a micrograined Al-Mg-Sc alloy produced by friction stir processing. Scr. Mater. 2008, 59, 882-885. [CrossRef]

13. Liu, F.C.; Ma, Z.Y. Contribution of grain boundary sliding in low-temperature superplasticity of ultrafine-grained aluminum alloys. Scr. Mater. 2010, 62, 125-128. [CrossRef]

14. Liu, F.C.; Ma, Z.Y.; Chen, L.Q. Low-temperature superplasticity of Al-Mg-Sc alloy produced by friction stir processing. Scr. Mater. 2009, 60, 968-971. [CrossRef]

15. Liu, F.C.; Xue, P.; Ma, Z.Y. Microstructural evolution in recrystallized and unrecrystallized Al-Mg-Sc alloys during superplastic deformation. Mater. Sci. Eng. A 2012, 547, 55-63. [CrossRef]

16. Malopheyev, S.; Mironov, S.; Vysotskiy, I.; Kaibyshev, R. Superplasticity of friction-stir welded Al-Mg-Sc sheets with ultrafine-grained microstructure. Mater. Sci. Eng. A 2016, 649, 85-92. [CrossRef]

17. Li, M.; Pan, Q.; Wang, Y.; Shi, Y. Fatigue crack growth behavior of Al-Mg-Sc alloy. Mater. Sci. Eng. A 2014, 598, 350-354. [CrossRef]

18. Argade, G.R.; Kumar, N.; Mishra, R.S. Stress corrosion cracking susceptibility of ultrafine grained Al-Mg-Sc alloy. Mater. Sci. Eng. A 2013, 565, 80-89. [CrossRef] 
19. Prangnell, P.B.; Heason, C.P. Grain structure formation during friction stir welding observed by the 'stop action technique'. Acta Mater. 2005, 53, 3179-3192. [CrossRef]

20. Tarasov, S.Y.; Filippov, A.V.; Kolubaev, E.A.; Kalashnikova, T.A. Adhesion transfer in sliding a steel ball against an aluminum alloy. Tribol. Int. 2017, 115, 191-198. [CrossRef]

21. Das, S.; Morales, A.T.; Alpas, A.T. Microstructural evolution during high temperature sliding wear of Mg-3\% Al-1\% Zn (AZ31) alloy. Wear 2010, 268, 94-103. [CrossRef]

22. Johnson, K.L.; Kauzlarich, J.J. Transfer of material between rolling and sliding surfaces. Int. J. Mech. Sci. 2004, 46, 343-357. [CrossRef]

23. Tongne, A.; Jahazi, M.; Feulvarch, E.; Desrayaud, C. Banded structures in friction stir welded Al alloys. J. Mater. Process. Tech. 2015, 221, 269-278. [CrossRef]

24. Schmidt, H.N.B.; Dickerson, T.L.; Hattel, J.H. Material flow in butt friction stir welds in AA2024-T3. Acta Mater. 2006, 54, 1199-1209. [CrossRef]

25. Chhangani, S.; Masa, S.K.; Mathew, R.T.; Prasad, M.J.N.V.; Sujata, M. Microstructural evolution in Al-Mg-Sc alloy (AA5024): Effect of thermal treatment, compression deformation and friction stir welding. Mater. Sci. Eng. A 2020, 772, 138790. [CrossRef]

26. Belyakov, A.; Kimura, Y.; Tsuzaki, K. Microstructure evolution in dual-phase stainless steel during severe deformation. Acta Mater. 2006, 54, 2521-2532. [CrossRef]

27. De Pari, L., Jr.; Misiolek, W.Z. Theoretical predictions and experimental verification of surface grain structure evolution for AA6061 during hot rolling. Acta Mater. 2008, 56, 6174-6185.

28. Masyukov, S.A. The Effect of Rolling on the Texture, Inhomogeneity of Precipitation of Dispersed Phases and Recrystallization AmG6, 1420 and 1570 Alloys. Ph.D. Thesis, MATI RGTU, Moscow, Russia, 2004.

(C) 2020 by the authors. Licensee MDPI, Basel, Switzerland. This article is an open access article distributed under the terms and conditions of the Creative Commons Attribution (CC BY) license (http://creativecommons.org/licenses/by/4.0/). 